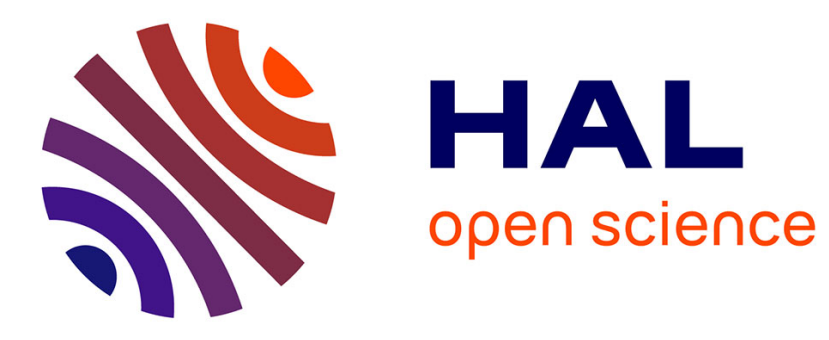

\title{
Radiation hybrid mapping of genes and newly identified microsatellites in candidate regions for bovine arthrogryposis-palatoschisis and progressive ataxia based on comparative data from man, mouse and rat
}

Amandine Duchesne, Andre A. Eggen

\section{To cite this version:}

Amandine Duchesne, Andre A. Eggen. Radiation hybrid mapping of genes and newly identified microsatellites in candidate regions for bovine arthrogryposis-palatoschisis and progressive ataxia based on comparative data from man, mouse and rat. Journal of Animal Breeding and Genetics, 2005, 122 (S 1), pp.28-35. 10.1111/j.1439-0388.2005.00493.x . hal-02676950

\section{HAL Id: hal-02676950 \\ https://hal.inrae.fr/hal-02676950}

Submitted on 31 May 2020

HAL is a multi-disciplinary open access archive for the deposit and dissemination of scientific research documents, whether they are published or not. The documents may come from teaching and research institutions in France or abroad, or from public or private research centers.
L'archive ouverte pluridisciplinaire HAL, est destinée au dépôt et à la diffusion de documents scientifiques de niveau recherche, publiés ou non, émanant des établissements d'enseignement et de recherche français ou étrangers, des laboratoires publics ou privés. 


\title{
Radiation hybrid mapping of genes and newly identified microsatellites in candidate regions for bovine arthrogryposis-palatoschisis and progressive ataxia based on comparative data from man, mouse and rat
}

\author{
A. Duchesne \& A. Eggen \\ Laboratoire de Génétique biochimique et de Cytogénétique, INRA-CRJ, Jouy-en-Josas, France
}

\author{
Correspondence \\ André Eggen, Laboratoire de Génétique \\ biochimique et de Cytogénétique, INRA-CRJ, \\ 78350 Jouy-en-Josas, France. \\ Tel: 33 (0)1 346524 24; Fax: 33 (0)1 346524 \\ 78; E-mail: eggen@jouy.inra.fr \\ Received: 1 July 2004; \\ accepted: 5 November 2004
}

\begin{abstract}
Summary
A comparative pathology and mapping strategy was used to initiate a study on two bovine genetic diseases: arthrogryposis-palatoschisis and progressive ataxia, which affect mainly Charolais cattle. Bibliographic studies provided information on the pathology of these diseases, which helped to define similar diseases in other species. Animals affected by bovine arthrogryposis-palatoschisis display similar symptoms to those of muscular dysgenesis, mouse mutants and animals with progressive ataxia to those of Long Evans Shaker rat mutants. Candidate regions are respectively human chromosome 1q32 (BTAl6) containing the gene CACNAlS and human chromosome 18q23 (BTA24) containing the gene myelin basic protein (MBP). Primer pairs were designed for 15 loci around each candidate gene, in a region of about 20 megabases and were used to screen a bovine Bacterial Artificial Chromosome (BAC) library. Eighteen microsatellites were found in the identified BAC clones, 11 on BTA24 and seven on BTAl6. The genes and microsatellites were mapped by radiation hybrid (RH) analysis and a $\mathrm{RH}$ map was obtained for each region with 18 new localizations on BTAl6 and 23 on BTA24. Comparative humanbovine analysis of the MBP region shows a good conservation of gene order while that of the CACNAlS region shows several breakpoints.
\end{abstract}

\section{Introduction}

Over the past decades, animal breeders, veterinarians and scientists have been interested in improving the description of the phenotypes of their favourite animals: breeders in order to increase production levels (milk, meat), veterinarians to better understand the biological processes causing pathologies, and scientists to decipher the genomic information underlying the observed phenotypic variations (of both production traits and pathologies). With increased population surveys in cattle, a growing number of genetic disorders has been identified and described (Huston et al. 2000). Currently,
357 bovine genetic disorders are described (http:// www.angis.org.au/Databases/BIRX/omia/) and for 27 of these, the causative mutation has been identified at the DNA level. According to Huston (1993), most of the disorders are autosomal recessive $(60 \%)$ or dominant $(20 \%)$. While genetic abnormalities are described in almost every breed of cattle, the occurrence varies among breeds. For example, because of artificial insemination (AI) and to the particular structure of the dairy bovine population (heavy use of a few very popular AI sires in dairy populations like the Holstein breed resulting in increased inbreeding), dairy breeds present a large palette of different disorders with some at a 
relative high frequency. This results in economical losses but also has a negative impact on selection image: this is best illustrated by the recent outspread of the complex vertebral malformation syndrome in Holstein cattle (Agerholm et al. 2001).

A closer physiological study of the 357 disorders shows that 117 could provide potential animal models for human disorders, justifying therefore the need to better describe and understand the ontogenesis of these disorders. However, as detailed physiological studies for these disorders are not always available in cattle, it is necessary to use the often well described phenotypes in man and the growing information coming from intensive studies in other mammals, namely mouse and rat: in these two species, systematic gene analyses are in progress using a variety of modern investigation techniques such as systematic knock-out, homologous recombination and genome sequencing (Nolan et al. 2000; The Mouse Genome Sequencing Consortium 2002; Rat Genome Sequencing Project Consortium 2004). Furthermore, as genomes of different mammalian species exhibit a high degree of similarity, it is appropriate to make proper use of comparative mapping and comparative physiology.

Here, we describe a combined comparative mapping and functional candidate gene approach in order to initiate the genetic characterization of two bovine genetic disorders affecting the Charolais cattle: arthrogryposis-palatoschisis syndrome and progressive ataxia. First, bibliographic studies provided information concerning the pathology of these disorders, most probably autosomal and recessive, (Palmer et al. 1972; Jackson 1978; Huston et al. 2000), which helped to identify similar diseases in other species. As a second step, comparative linkage and radiation hybrid (RH) maps together with a BAC-based physical map of the bovine genome were used to identify target chromosomal regions from which polymorphic markers were detected and to determine the extent of similar gene content and/or gene order between specific segments of the human and the bovine genomes. Both disorders could serve as potential animal models to better understand and dissect human disorders where similar phenotypes exist as being part of a more complex syndrome. In the near future, with the availability of the sequence of the bovine genome, comparative mapping combined with identification of candidate genes will be more effective and will permit faster identification of relevant markers and putative positional and functional candidate genes for genetic disorders.

\section{Materials and methods}

\section{Comparative pathology}

For both diseases, arthrogryposis-palatoschisis syndrome and progressive ataxia, bibliographic studies provided information concerning the pathology, which helped to identify similar diseases in other species (Palmer et al. 1972; Jackson 1978; Huston et al. 2000). Animals affected by bovine arthrogryposis-palatoschisis display similar symptoms to those of muscular dysgenesis (mdg) mouse mutants: in both species, newborn animals are smaller than normal ones, with a fixation of posture at multiple joints and a cleft palate in around $70 \%$ of the cases. They suffer from generalized muscular weakness, originating from the disorganization of the muscle's structure, particularly in the Z-band. Additionally, there is an abnormal differentiation of neuromuscular junctions in mouse, and this may also be the case in cattle (Pai 1965; Banker 1977; Drouet et al. 1993; Luo et al. 1996). Animals with progressive ataxia display similar symptoms to those of Long Evans Shaker (LES) rat mutants. Clinical signs are weakness of the hind limbs, which slowly progress to ataxia, and sometimes to total paralysis. These two ataxia are disorders of the central white matter, and the main abnormality is dysmyelination (Delaney et al. 1995; Kwiecien et al. 1998, 2000). Based on this information and on the demonstration that $m d g$ in mice is caused by a genetic disruption of the coding sequence for the CACNAIS mRNA (calcium channel, voltage-dependent, L-type, alpha-1S subunit; Chaudari 1992) and LES in rat is because of the insertion of an endogenous retrotransposon into a non-coding region (intron 3) of the Myelin Basic Protein (MBP) gene ( $\mathrm{O}^{\prime}$ Connor et al. 1999), a functional candidate gene was identified for each bovine disorder. By comparative mapping between mouse and man for $m d g$ and between rat and man for LES, candidate regions were identified and used as a basis to find the homologous bovine segment. Candidate regions were thus defined, respectively, human chromosome lq32 (containing the gene CACNAls and corresponding to bovine chromosome 16, BTAl6) and human chromosome 18q23 (containing the gene MBP and corresponding to bovine chromosome 24, BTA24) as defined by chromosome painting (Hayes 1995).

\section{Primers}

Fifteen loci were selected around each candidate gene (CACNAIS and MBP), in a segment of about 
20 megabases. Primer pairs were designed from available bovine EST sequences using the 'Interspecific Comparative Clustering and Annotation for Est' user interface (ICCARE: http://genopole.toulouse.inra.fr/bioinfo/Iccare/). Primer sequences and sizes of the amplified target segments are given in Table 1.

\section{Bovine BAC identification}

The PCR-based screening for each locus was performed on the four-genome equivalent INRA bovine BAC library containing 105984 clones (Eggen et al. 2001). PCR conditions are described in Gautier et al. (2002).

\section{Microsatellite isolation}

Microsatellites were isolated from BAC clones containing each selected locus, after digestion with Sau3AI (Promega, Madison, WI, USA), subcloning and hybridization with fluorescent (TG/TC) 12 (Roche Diagnostics, Mannheim, Germany). After partial sequencing of the positive clones, primers for PCR amplification were designed to specifically amplify these microsatellite regions. The polymorphism of 10 BTA24 microsatellites was tested on 44 animals from different breeds on 5\% acrylamide denaturating gels. Microsatellites characteristics are given in Table 2.

Bovine whole-genome $\mathrm{RH}$ panel genotyping and map construction

The loci (genes and microsatellites) were mapped by PCR on the 94-cell lines RH panel described by Williams et al. (2002) and the CARTHAGENE software (Schiex \& Gaspin (1997) was used to perform twopoint and multipoint analyses of the $\mathrm{RH}$ data and to provide comprehensive maps of the two regions.

\section{Results}

BAC library screening and microsatellite identification

Of the 30 selected genes used to screen the BAC library, at least one BAC clone was identified for 25 genes (see Table 1). After sub-cloning of the BAC clones, 45 microsatellites were identified by sequencing, five of them being duplicates: the ratios of the structures of the repeat motifs were similar to those described by Vaiman et al. (1994) with $80 \%$ of (TG/ $\mathrm{CA})_{n}, 9 \%$ of $(\mathrm{TC} / \mathrm{GA})_{n}$ and $9 \%$ of $(\mathrm{GTC})_{\mathrm{n}}$ or $(\mathrm{TGC})_{\mathrm{n}}$. Because of the proximity of the Sau3AI restriction site to the microsatellite motif for some sequences, primers were designed for 23 microsatellites and 18 were found useful, as reported in Table 2 .

\section{RH mapping and comparative maps}

Specific amplification of the bovine DNA in RH was obtained for $77 \%$ of the genes and $90 \%$ of the microsatellites. For the remaining loci, three kinds of results were observed: a PCR product of the same size for both the hamster and the bovine DNA (C3IP1, HSPC060, MYOG and FLJ20307), a PCR product without a clear pattern (INRA297 and INRA319) or no PCR product (FHR, RNPEP and LAMB3). Data were analysed with the CARTHAGENE software and comprehensive maps were built for both regions integrating markers previously reported by Williams et al. (2002), the bovine genes and the newly developed microsatellites (see Figure 1 for BTA16 and Figure 2 for BTA24).

Of the 15 genes mapping to the flanking regions of the candidate gene CACNAls in man (HSAlBTA16), 11 were successfully mapped with the bovine RH panel and could be integrated in a comprehensive RH map for BTAl6 based on markers already mapped by Williams et al. (2002). The comprehensive comparative map between BTAl6 and HSAl (lq25-1q32 region) exhibits three conserved syntenic segments (S1, S2, S3) (Figure 1): S1 and S3 are next to each other in cattle and localized in the centromeric region of BTA16, while S2, localized in human between the $\mathrm{S} 1$ and S3, maps to the telomeric region of BTAl6. It should be noted that the S2 segment containing the candidate gene CACNA1S, maps to the distal part of BTAl6, therefore, despite the seven newly identified microsatellites, we found no markers flanking the candidate gene. Therefore, it is necessary to identify more markers in the telomeric region of BTAl6. Furthermore, markers are unequally spread over the three bovine segments, with $85 \%$ in the first centromeric segments $(\mathrm{S} 1+\mathrm{S} 3)$.

For BTA24, 23 loci (12 genes and 11 microsatellites) were mapped to the bovine region corresponding to HSAl8 containing the candidate segment around the MBP gene. The bovine gene order obtained is in perfect agreement with the human map for the studied region, except for very close genes, for which discrimination is impossible because of the limit of resolution of the $\mathrm{RH}$ panel. Our $\mathrm{RH}$ map is perfectly integrated to the previous published one (Williams et al. 2002) and has a mean density of one marker every $543 \mathrm{~kb}$ (as measured on the 
Table 1 Characteristics of the designed primer pairs

\begin{tabular}{|c|c|c|c|c|c|c|}
\hline Locus name ${ }^{1}$ & BTA $^{2}$ & $\mathrm{HSA}^{3}$ & $\mathrm{HSA} \mathrm{Mb^{4 }}$ & Primer sequence $5^{\prime}-3^{\prime}$ & Size (bp) & BAC clones adresses \\
\hline \multirow[t]{2}{*}{ PTGS2 } & \multirow[t]{2}{*}{16} & \multirow[t]{2}{*}{$1 q 25.2-q 25.3$} & \multirow[t]{2}{*}{218.91} & GGTAGAAGCTGGAGCACCATT & \multirow[t]{2}{*}{199} & 0172F02 \\
\hline & & & & GGTGAGGTGCGTATCTTGAAC & & 0531F07 \\
\hline \multirow[t]{2}{*}{ RGS2 } & \multirow[t]{2}{*}{16} & \multirow[t]{2}{*}{$1 q 31$} & \multirow[t]{2}{*}{225.59} & CAAAACTCTGATTGCCCAAAA & \multirow[t]{2}{*}{152} & $0013 G 06$ \\
\hline & & & & TGATCTGGGGCTTTTTACACA & & $0591 \mathrm{G} 03$ \\
\hline \multirow[t]{2}{*}{$\mathrm{UCH} 37$} & \multirow[t]{2}{*}{16} & \multirow[t]{2}{*}{$1 q 32$} & \multirow[t]{2}{*}{225.76} & AAGCAGAATGCAAAGAAAGCA & \multirow[t]{2}{*}{182} & \multirow[t]{2}{*}{ 0486E10 } \\
\hline & & & & CCATGCATTAAAGACAAGACAGA & & \\
\hline \multirow[t]{2}{*}{ B3GALT2 } & 16 & $1 q 31$ & 225.91 & TTGGAAAGAAACTGTCCCTCA & 192 & 0277B07 \\
\hline & & & & CACTTTTCGGGTTCGTTGATA & & $0930 \mathrm{H} 10$ \\
\hline FHR & 16 & $1 q 32$ & 229.73 & ACCTTGTCATTTTCCCGACAT & 165 & - \\
\hline & & & & CCATCTTGTGTGCAATGAATG & & \\
\hline ZNF281 & 16 & $1 \mathrm{q} 32.1$ & 233.86 & GCGTTTGGTTCTCAGTTCAAG & 202 & 0126H02 \\
\hline & & & & СACTCCTGGGACCTTACCTGT & & 0375C04 \\
\hline CACNA1S & 16 & $1 q 32$ & 234.39 & СTTCCTGGAAAGGACCAACTC & 160 & $0114 F 06$ \\
\hline & & & & GTTGTTGGTGTTGGCACGAG & & 0340A11 \\
\hline PKP1 & 16 & $1 q 32$ & 234.76 & GTACCAGCTGGGTGGCATCT & 205 & $0183 \mathrm{H} 11$ \\
\hline & & & & GGTCAGCTGCTTCTGGATCT & & $0942 \mathrm{G} 10$ \\
\hline RNPEP & 16 & $1 q 32$ & 235.55 & ACCTTACCTCCCGGACCTCT & 174 & - \\
\hline & & & & GGGGACTTCTGCAGGATCTTA & & \\
\hline C3IP1 & 16 & 1 & 236.87 & GCTTGATGAGAGGCATTATGG & 191 & 0245E06 \\
\hline & & & & GAACATGGCGCAGAAGTAATC & & 0427D04 \\
\hline MYOG & 16 & $1 q 31-q 41$ & 237.01 & GGGCGTGTAAGGTGTGTAAGA & 194 & 0605D06 \\
\hline & & & & CAGGCGCTCTATGTACTGGAT & & 0765E05 \\
\hline BTG2 & 16 & $1 q 32$ & 237.23 & TGGACCCCATCATCAGTAAAG & 205 & 0685B06 \\
\hline & & & & ATCATTTGGTTCTTGCAGGTG & & 0808F03 \\
\hline ELK4 & 16 & $1 q 32$ & 239.92 & GCTATCACCCTGTGGCAGTT & 176 & 0644C07 \\
\hline & & & & GCTCGGCTGAGTTTGTCATAA & & 0968D06 \\
\hline DYRK3 & 16 & $1 q 32$ & 240.96 & GTGCCTCTGACTCCAGAACAG & 193 & 0967H01 \\
\hline & & & & CTCGAGGCACGTGAATATAGG & & $0976 C 09$ \\
\hline LAMB3 & 16 & $1 q 32$ & 244.27 & CTCAGCAGGTCTCGGACAG & 170 & - \\
\hline & & & & GTTGATGGTGGGCGTCAG & & \\
\hline FLJ20281 & 24 & $18 q 22$ & 70.25 & ACTTTGGCAACAGTTCACCAC & 100 & $0927 C 07$ \\
\hline & & & & CTTAGTGACGGGACACTGACA & & \\
\hline HSPC060 & 24 & $18 q 22$ & 78.62 & АTCTCCTTCCCGTAGCAGCTC & 132 & - \\
\hline & & & & GACCTTCCGGAAATCTTTCAA & & \\
\hline HSPC154 & 24 & $18 q 23$ & 83.32 & AGACTGAGCCCAGGTGGAG & 153 & $0194 G 06$ \\
\hline & & & & TGTGCACAGACACTTGCTTG & & 0543H04 \\
\hline CYB5 & 24 & $18 q 23$ & 83.44 & CTGGTGGGGAGGAAGTCTTA & 129 & $1088 \mathrm{G} 11$ \\
\hline & & & & CCAATGATGAACGTTTTGGAC & & \\
\hline FLJ10830 & 24 & $18 q 23$ & 83.73 & CTGGAGGGCATGGAGGAGT & 141 & 0619C08 \\
\hline & & & & GTAGGTGATGCAGGGCTTGT & & 0772C09 \\
\hline & & & & & & $0778 \mathrm{~B} 03$ \\
\hline FLJ20307 & 24 & $18 q 23$ & 84.19 & GTCAAACTGCGCTGAAAACAT & 200 & - \\
\hline & & & & CGTAGGACTTGGACACAATGC & & \\
\hline ZNF236 & 24 & $18 q 22-q 23$ & 86.36 & GCAAGGGGTTTGTTTAATTCC & 200 & 0569C03 \\
\hline & & & & ACATCAATGTCTTGGGTTTGC & & \\
\hline MBP & 24 & $18 q 23$ & 86.51 & ACAGAAGAGACCCTCCCAGAG & 113 & 0791A05 \\
\hline & & & & AGTCGAGGATGCCAGTGTCT & & 0894H05 \\
\hline NFATC1 & 24 & $18 q 23$ & 89.30 & GTGCAACAAGCGCAAGTACG & 144 & 0514B05 \\
\hline & & & & GAGCTGGTGTACTGTGTGGTG & & $0525 C 02$ \\
\hline & & & & & & 0547B02 \\
\hline CTDP1 & 24 & $18 q 23$ & 89.58 & TATGCCAAGTATGACCGCTTC & 120 & $0812 \mathrm{E} 02$ \\
\hline & & & & CAGCCCGCTGAAGATGATG & & $0872 \mathrm{H} 11$ \\
\hline FLJ22378 & 24 & $18 q 23$ & 89.82 & СTTCAAGACGGCCTACTTCCT & 133 & 0470G09 \\
\hline & & & & GGCTGGCTTCAGAGGGTAG & & $0763 C 06$ \\
\hline DIM1 & 24 & $18 q 23$ & 89.88 & ACCGGCAACAACAACAAGAT & 127 & 0460F08 \\
\hline & & & & TGGAGTAGTCCTTCGGAGACA & & 0470G09 \\
\hline & & & & & & 0696H10 \\
\hline
\end{tabular}


Table 1 Continued

\begin{tabular}{|c|c|c|c|c|c|c|}
\hline Locus name ${ }^{1}$ & BTA $^{2}$ & $\mathrm{HSA}^{3}$ & HSA Mb ${ }^{4}$ & Primer sequence $5^{\prime}-3^{\prime}$ & Size (bp) & BAC clones adresses \\
\hline KIAA0863 & 24 & $18 q 23$ & 90.07 & $\begin{array}{l}\text { AACTGCGTGTTTTCCTCTCAA } \\
\text { GCTACCAGCACATGCTTCTTC }\end{array}$ & 202 & $\begin{array}{l}\text { 0553F07 } \\
\text { 0712E08 } \\
\text { 0104F06 } \\
\text { 0371F07 }\end{array}$ \\
\hline FLJ21172 & 24 & $18 q 23$ & 90.08 & $\begin{array}{l}\text { CACAAGTCATCCCAGTTGGAG } \\
\text { GTTCAAGTCGCACAACTCCTG }\end{array}$ & 159 & $\begin{array}{l}0068 \mathrm{~F} 05 \\
0556 \mathrm{E} 12\end{array}$ \\
\hline PARD6G & 24 & $18 q 23$ & 90.13 & $\begin{array}{l}\text { ACGTTGTTCCTCTGGTTGG } \\
\text { GTCAATGACGAAGTCCTGGAG }\end{array}$ & 134 & 0316H10 \\
\hline
\end{tabular}

${ }^{1}$ The exact denomination of each locus can be found at: http://www.ncbi.nlm.nih.gov.

${ }^{2}$ Bovine localization.

${ }^{3}$ Human cytogenetic localization.

${ }^{4}$ Position in megabases on the corresponding human chromosome (NCBI build 30).

Table 2 Characteristics of the microsatellites identified for the two candidate chromosome segments

\begin{tabular}{|c|c|c|c|c|c|c|c|}
\hline BTA & Microsatellite & Structure & In locus & $\begin{array}{l}\text { Isolated from } \\
\text { BAC clone }\end{array}$ & Primer sequence $5^{\prime}-3^{\prime}$ & Size & $\begin{array}{l}\text { Polymorphism: } \\
\text { number of alleles }\end{array}$ \\
\hline 16 & INRA297 & $(\mathrm{CA})_{10}$ & BTG2 & 0685B06 & $\begin{array}{l}\text { CAGTTTCTGCTGCTCTCAACA } \\
\text { ACACAACCTCACCTCACCTTT }\end{array}$ & 149 & - \\
\hline 16 & INRA298 & $(\mathrm{CA})_{21}$ & RGS2 & $0591 \mathrm{G} 03$ & $\begin{array}{l}\text { GGAGGAGGCTCTCGGTAAAC } \\
\text { GTTGGACACGACTGAGCAACT }\end{array}$ & 189 & - \\
\hline 16 & INRA299 & $(\mathrm{TG})_{12} \mathrm{TACA}(\mathrm{TG})_{5} \mathrm{TATA}(\mathrm{TG})_{6}$ & DYRK3 & 0486E10 & $\begin{array}{l}\text { AGCTCATGTTCCTGCTCTCTG } \\
\text { TTCCAATCATGAGAACACAGC }\end{array}$ & 205 & - \\
\hline 16 & INRA301 & $(\mathrm{CA})_{18}$ & ELK4 & $0644 C 07$ & $\begin{array}{l}\text { AAGTCAGCTGTGGAAAAACCA } \\
\text { TTTCTCCAATATCCAGCCAGA }\end{array}$ & 202 & - \\
\hline 16 & INRA306 & $(\mathrm{CA})_{11}$ & ELK4 & 0644C07 & $\begin{array}{l}\text { GAGTGACAGGAAAATGGGAGT } \\
\text { GATTTTGAGCTCATCCAGTTTTT }\end{array}$ & 205 & - \\
\hline 24 & INRA309 & $(\mathrm{TG})_{16}$ & CYB5 & 1088G11 & $\begin{array}{l}\text { GGGAGCTCTCTGGAGTCTCTG } \\
\text { CAACCCATTCCAGTGTTCTTG }\end{array}$ & 196 & 5 \\
\hline 24 & INRA310 & $(\mathrm{GT})_{10}$ & MBP & 0791A05 & $\begin{array}{l}\text { GTAGCCTGAGCCCTCTCACTT } \\
\text { GAAATGCCATGACCAGAGAAG }\end{array}$ & 216 & 1 \\
\hline 24 & INRA311 & $(\mathrm{TG})_{14}$ & FLJ10830 & 0619C08 & $\begin{array}{l}\text { CAGTCTGAGAACACATATTAC } \\
\text { TTCCAGATTACAGGAGGCTGA }\end{array}$ & 189 & 5 \\
\hline 24 & INRA312 & $(\mathrm{TG})_{15} \mathrm{TC}(\mathrm{TG})_{4}$ & KiAA0863 & 0553F07 & $\begin{array}{l}\text { CAGGCGGGTTCTTTACCACTA } \\
\text { TCCACAAGAATGCTTTTCACC }\end{array}$ & 192 & 7 \\
\hline 16 & INRA313 & $(\mathrm{TC})_{8}$ & MYOG & 0605D06 & $\begin{array}{l}\text { AGATACCTTGCAACCCGTCTC } \\
\text { AGCAGGACGGTAAGGGCTAT }\end{array}$ & 195 & - \\
\hline 24 & INRA316 & $(\mathrm{CA})_{11}$ & FLJ20281 & 0927C07 & $\begin{array}{l}\text { AGAATCCCATGGACAGAGGAG } \\
\text { TGGGAACCATTCCTGTAAAAG }\end{array}$ & 198 & 2 \\
\hline 24 & INRA317 & $(\mathrm{CA})_{14}$ & FLJ10830 & 0772C09 & $\begin{array}{l}\text { TTACAGGAGGCTGAGGAGACA } \\
\text { CAGTCTGAGAACACATATCACA }\end{array}$ & 182 & 6 \\
\hline 24 & INRA318 & $(\mathrm{TGC})_{3} \mathrm{TAC}(\mathrm{TGC})_{4}$ & $\begin{array}{l}\text { DIM1 } \\
\text { FLJ22378 }\end{array}$ & $\begin{array}{l}\text { 0470G02 } \\
0460 G 09 \\
0783 G 06\end{array}$ & $\begin{array}{l}\text { GCTGTGAGGCAACACATTTCT } \\
\text { ATGGGGTCACACAAGAGTCAG }\end{array}$ & 210 & 1 \\
\hline 24 & INRA319 & $(\mathrm{GTC})_{5} \mathrm{AA}(\mathrm{GTC})$ & ZNF236 & 0569C03 & $\begin{array}{l}\text { TGAGGCATCTCACTGATGACA } \\
\text { ACAGAGTCGGACACGACTGAA }\end{array}$ & 146 & 6 \\
\hline 24 & INRA320 & $(\mathrm{CA})_{15}$ & $\begin{array}{l}\text { KIAA0863 } \\
\text { FLJ21172 }\end{array}$ & $\begin{array}{l}\text { 0371F07 } \\
\text { 0556E12 }\end{array}$ & $\begin{array}{l}\text { TTTGTGTGTTGCCAGGTACAG } \\
\text { GAGCTCTTTGGGAGGGTACTG }\end{array}$ & 199 & 7 \\
\hline 24 & INRA321 & $(\mathrm{GT})_{20}$ & KIAA0863 & 0371F07 & $\begin{array}{l}\text { CGTACCTTGAGGCTGAGACTG } \\
\text { AGCCTGGTGAGTGAGCTACAG }\end{array}$ & 191 & 7 \\
\hline 24 & INRA323 & $(\mathrm{AC})_{21}$ & MBP & 0894H05 & $\begin{array}{l}\text { TCTGTATTGCACCTCCTCCAC } \\
\text { GGCTGCTCTGCTGTAGTTTCA }\end{array}$ & 198 & - \\
\hline
\end{tabular}




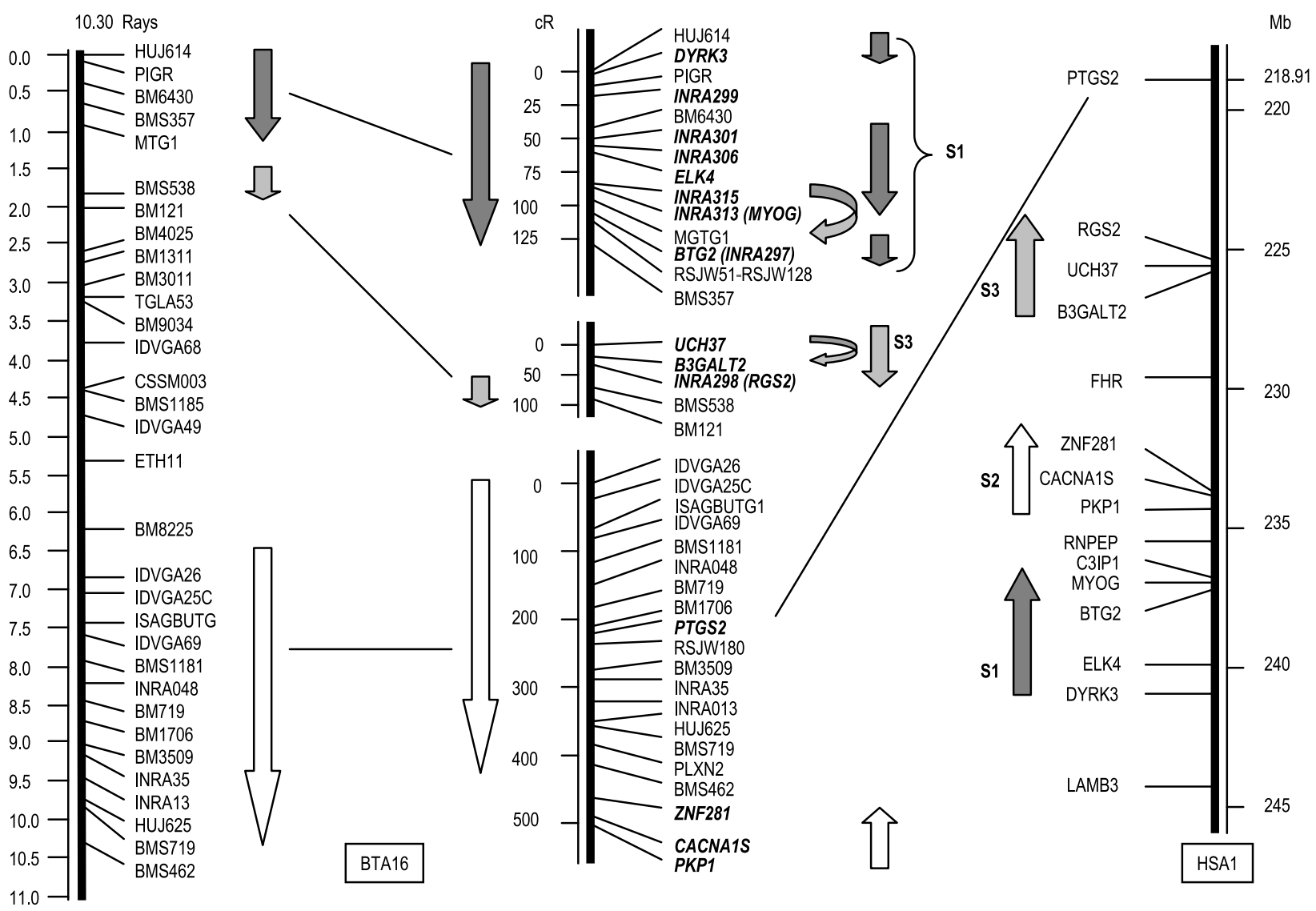

Figure 1 Comparative mapping between human chromosome 1 (HSA1) and bovine chromosome 16 (BTA16). Distances are expressed in centiRays for BTA16 and megabasepairs for HSA1 (NCBI build 30). Localization uncertainties are shown by curved arrows. Loci in bold and italic were mapped during this work; others are from Williams et al. (2002). Mapping information for the loci in brackets were inferred from BAC information content.

human genome). The informativity of 10 of the newly identified microsatellites (BTA24) was assessed by testing their polymorphism: seven are highly polymorphic displaying five to seven alleles and will therefore be useful for further linkage studies.

\section{Discussion}

We described a combined comparative mapping and functional candidate gene approach in order to initiate the genetic characterization of two bovine genetic disorders, arthrogryposis-palatoschisis syndrome and progressive ataxia, affecting the Charolais cattle. Using the available comparative mapping information, we were able to map, respectively, $11+12$ new genes on BTAl6 and BTA24 and to identify and map $7+11$ new microsatellite markers in the candidate comparative segments on BTAl6 and 24 . Therefore, useful information has been added to the bovine map, confirming and refining, for those chromosomes, a recent comparative study published by Hayes et al. (2003).

As our candidate regions are based on comparative physiological studies, the next step in the identification process of the underlying genes for these bovine disorders is to test the candidate region with the obtained polymorphic microsatellites in affected pedigree either by linkage analysis, homozygozity mapping or linkage disequilibrium studies. This is certainly a limiting step, because even if the disorder is relatively frequent in the population, collecting samples from affected animals is not easy. Indeed, breeders do not systematically report cases, and breeder organizations are not always motivated to exchange information on genetic disorders, especially if some famous genitors are involved in the disease. This is typically the case for the two disorders reported in this paper. In the future, systematic collection of such data together with biological samples will be enhanced by national surveillance programmes and international collaborations. 


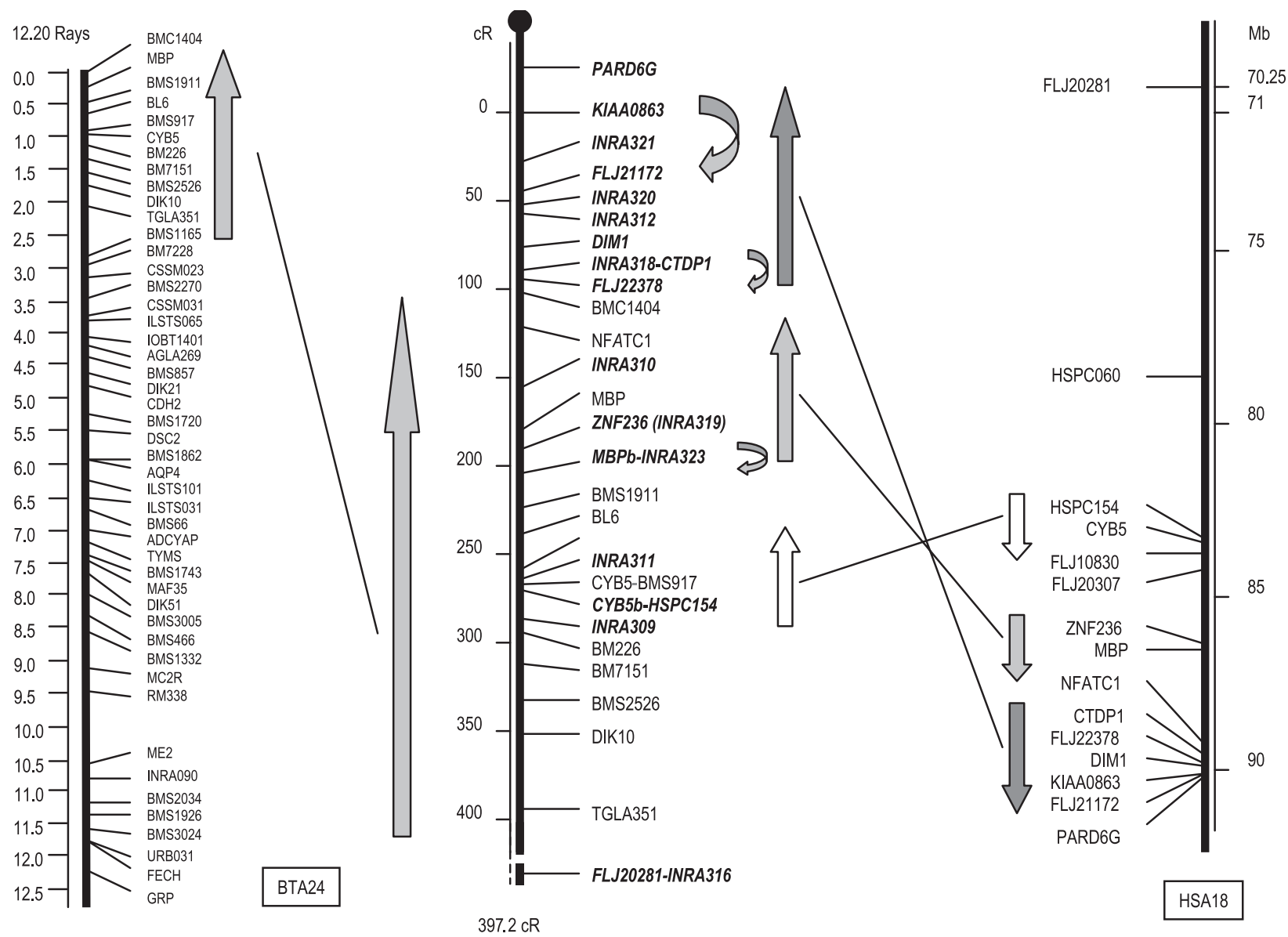

Figure 2 Comparative mapping between human chromosome 18 (HSA18) and bovine chromosome 24 (BTA24). Distances are expressed in centiRays for BTA16 and megabasepairs for HSA1 (NCBI build 30). Localization uncertainties are shown by curved arrows. Loci in bold and italic were mapped during this work; others are from Williams et al. (2002). Mapping information for the loci in brackets were inferred from BAC information content. MBPb and CYB5b correspond to human genes MBP and CYB5 and have been previously mapped by Williams et al. (2002) (MBP et CYB5).

In the near future, with the publicly available sequence of the bovine genome (http:// hgsc.bcm.tmc.edu/projects/bovine/) the described approach will evolve into a pure in silico mapping process from the mapping of homologous genes to the identification of microsatellite markers. Furthermore, single nucleotide polymorphisms will be the choice markers as they are very abundant in the cattle genome, easily detected using in silico analysis of sequences of interest and can be integrated in high throughput genotyping projects. Comparative sequencing will also play a crucial role as it will help to identify not only the similar coding regions among species but also sequences with significant functional activities as shown by Boffeli et al. (2004). This trend best illustrates the fact that we are reaching the end of different mapping activities in livestock, and are now moving towards a sequencing era to further investigate the structural and functional organization of livestock genomes.

\section{Acknowledgements}

We thank Sead Taourit for technical assistance and Hélène Hayes for critical reading of the manuscript. A. Duchesne is a PhD student supported by a joint grant from INRA and LABOGENA.

\section{References}

Agerholm J.S., Bendixen C., Andersen O., Arnbjerg J. (2001) Complex vertebral malformation in holstein calves. J. Vet. Diagn. Invest., 13, 283-289.

Banker B.Q. (1977) Muscular dysgenesis in the mouse (mdg/mdg). J. Neuropathol. Exp. Neurol., 36, 100-127. 
Boffeli D., Nobrega M.A., Rubin E.M. (2004) Comparative genomics at the vertebrates extremes. Nat. Rev. Genet., 5, 456-465.

Chaudari N. (1992) A single nucleotide deletion in the skeletal muscle-specific calcium channel transcript of muscular dysgenesis (mdg) mice. J. Biol. Chem., 267, 25636-25639.

Delaney K.H., Kwiecien J.M., Wegiel J., Wisniewski H.M., Percy D.H., Fletch A.L. (1995) Familial dysmyelination in a Long Evans rat mutant. Lab. Anim. Sci., 45, 547-553.

Drouet B., Garcia L., Simon-Chazottes D., Mattei M.G., Guénet J.L., Schwartz A., Varadi G., Pincon-Raymond M. (1993) The gene coding for the $\alpha$ l subunit of the skeletal dihydropyridine receptor $($ Cchlla $3=m d g)$ maps to mouse chromosome 1 and human 1q32. Mamm. Genome., 4, 449-503.

Eggen A., Gautier M., Billaut A., Petit E., Hayes H., Laurent P., Urban C., Pfister-Genskow M., Eilertsen K., Bishop M.D. (2001) Construction and characterization of a bovine BAC library with four genome-equivalent coverage. Genet. Sel. Evol., 33, 543-548.

Gautier M., Hayes H., Eggen A. (2002) An extensive and comprehensive radiation hybrid map of bovine chromosome 15: comparison with human chromosome 11. Mamm. Genome., 13, 316-319.

Hayes H. (1995) Chromosome painting with human chromosome-specific DNA libraries reveals the extent and distribution of conserved segments in bovine chromosomes. Cytogenet. Cell Genet., 71, 168-174.

Hayes H., Elduque C., Gautier M., Schibler L., Cribiu E.P., Eggen A. (2003) Mapping of 195 genes in cattle and updated comparative map with man, mouse, rat and pig. Cytogenet. Cell Genet., 102, 16-24.

Huston K. (1993) Heritability and diagnosis of congenital abnormalities in food animals. The veterinary clinics of North America. Food Anim. Pract., 19, 1-10.

Huston K., Saperstein G., Steffen D., Millar P., Lauvergne J.J. (2000) Clinical, pathological and other visible traits loci except coat colour (category 2). In: P. Millar, J.J. Lauvergne, C. Dolling (eds), Mendelian Inheritance in Cattle 2000, EAAP Publication, Wageningen, The Netherlands. (No. 101). pp. 107-117, 168-172, 184-185.

Jackson A.E. (1978) Congenital arthrogryposis in Charolais calves. Vet. Rec., 102, 149-150.

Kwiecien J.M., O'Connor L.T., Goetz B.D., Delaney K.H., Fletch A.L., Duncan I.D. (1998) Morphological and morphometric studies of the dysmyelinating mutant, the Long Evans shaker rat. J. Neurocytol., 27, 581-591.
Kwiecien J.M., Blanco M., Fox J.G., Delaney K.H., Fletch A.L. (2000) Neuropathology of bouncer Long Evans, a novel dysmyelinated rat. Comp. Med., 50, 503-510.

Luo Z.D., Pinçon-Raymond M., Taylor P. (1996) Acetylcholinesterase and nicotinic acetylcholine receptor expression diverge in muscular dysgenic mice lacking L-type calcium channel. J.Neurochem., 67, 111-118.

Nolan P.M., Peters J., Vizor L., Strivens M., Washbourne R., Hough T., Wells C., Glenister P., Thornton C., Martin J., Fisher E., Rogers D., Hagan J., Reavill C., Gray I., Wood J., Spurr N., Browne M., Rastan S., Hunter J., Brown S.D. (2000) Implementation of a large-scale ENU mutagenesis program: towards increasing the mouse mutant resource. Mamm. Genome., 11, 500-506.

O'Connor L.T., Goetz B.D., Kwiecien J.M., Delaney K.H., Fletch A.L., Duncan I.D. (1999) Insertion of a retrotransposon in Mbp disrupts mRNA splicing and myelination in a new mutant rat. J. Neurosci., 19, 34043413.

Pai A. (1965) Developmental genetics of a lethal mutation, Muscular Dysgenesis $(m d g)$, in the mouse. Dev. Biol., 11, 82-109.

Palmer A.C., Blakemore W.F., Barlow R.M., Fraser J.A, Ogden A.L. (1972) Progressive ataxia of Charolais cattle associated with a myelin disorder. Vet. Rec., 91, 592594.

Rat Genome Sequencing Project Consortium (2004) Genome sequence of the Brown Norway rat yields insights into mammalian evolution. Nature, 428, 493-521.

Schiex T., Gaspin C. (1997) CARTHAGENE: construsting and joining maximum liklihood genetic maps. Proc Int Conf Intell Syst Mol Biol 5, 258-267.

The Mouse Genome Sequencing Consortium (2002) Initial sequencing and comparative analysis of the mouse genome. Nature, 420, 520-562.

Vaiman D., Mercier D., Moazami-Goudarzi K., Eggen A., Ciampolini R., Lépingle A., Velmala R., Kaukinen J., Varvio S.L., Martin P., Levéziel H., Guérin G. (1994) A set of 99 cattle microsatellites: characterization, synteny mapping and polymorphism. Mammalian Genome 5, 288-297.

Williams J.L., Eggen A., Ferretti L., Farr C.J., Gautier M., Amati G., Ball G., Caramorr T., Critcher R., Costa S., Hextall P., Hills D., Jeulin A., Kiguwa S.L., Ross O., Smith A.L., Saunier K., Urquhart B., Waddington D. (2002) A bovine whole-genome radiation hybrid panel and outline map. Mamm. Genome, 13, 469-474. 